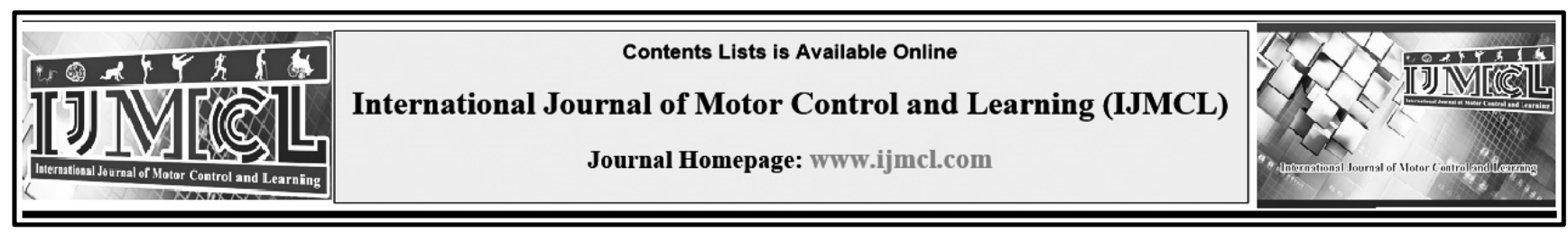

\title{
Let's Avoid Confusion in Notation of UCM Synergy Indexes
}

\author{
Mohammad Ali Sanjari ${ }^{a *}$ \\ ${ }^{a}$ Associate Professor of Biomechanics, Rehabilitation Research Center, and Department of Basic Rehabilitation Sciences, Faculty of Rehabilitation \\ Sciences, Iran University of Medical Sciences, Tehran, Iran. \\ * Corresponding E-mail: sanjarima@iums.ac.ir
}

Received: 2020/10/01 | Accepted: 2020/12/06 | Published: 2021/02/05

\section{DEAR EDITOR}

Uncontrolled Manifold (UCM) approach has gained a lot of attention in the field of movement variability and related areas of research. The diversity of applications and the need to explore new UCM-based measures along with the advances in mathematical methods in UCM have led to several formulas for UCM outcome measures with different notations and conflicting interpretations. This letter is intended to summarize the most popular indexes while suggesting a unified notation.

Starting from the seminal work of Scholz and Schöner (Scholz \& Schöner, 1999) many researchers have employed this approach to understanding the underlying principles of human movement and force/torque/posture control, as well as identifying corresponding control variables. In the UCM approach, the variability of elements (e.g. joint angles) is decomposed into two variances, those who affect the performance variable $\left(V_{U C M}\right)$ and those who don't $\left(V_{O R T}\right)$. These variances provide the basic ground to gain insight into the underlying phenomena like control of the center of mass to maintain a posture. However, several measures have been introduced as indexes of synergy which reflect the relative amount of these two kinds of variances. The simplest is the ratio $R=V_{U C M} / V_{O R T}$ which returns the relative amount of good variance to the bad variance (Black, Smith, Wu, \& Ulrich, 2007; Hsu, Scholz, Schoner, Jeka, \& Kiemel, 2007); others have denoted this by S (Verrel, 2010) or ME (motor equivalent index) (Hsu, Chou, \& Woollacott, 2013). Since in this index $V_{U C M}$ is normalized by $V_{O R T}, R$ is not sensitive to simultaneous change of both variances. To overcome this, some researchers have normalized the difference between the two variances to the sum of the variances $\quad R M V=\left(V_{U C M}-V_{O R T}\right) /\left(V_{U C M}+\right.$ $V_{O R T}$ ), perhaps assuming that the total variance is equal to the sum of variances. In 
some papers, this is symbolized as T (E. Park, Reimann, \& Schöner, 2016), D $\mathrm{V}_{\mathrm{VAR}}$ (E. Park, Schöner, \& Scholz, 2012), S (Gianikellis, Sánchez-Margallo, Skiadopoulos, Sánchez-Margallo, \& de Mendoza Aranda, 2015) or even R in (Papi, Rowe, \& Pomeroy, 2015; Tawy, Rowe, \& Biant, 2018); which in the latter case, could be mistaken with the simple ratio of variances. I suggest RMV for a relative measure of joint variances to avoid conflict with other measures as follows.

As another point, the total variance is not simply the sum of the two variances, hence their degrees of freedom (DoF) should be considered, i.e. the total variance is expressed as $V_{T O T}=\left[(n-d) V_{U C M}+d V_{O R T}\right] /$ $n$, where $n$ and $d$ are DoF of elemental and performance (task) variables, respectively (Verrel, 2010). Therefore, it is better to normalize the difference between the two variances to $V_{T O T}$ as $D V=\left(V_{U C M}-V_{O R T}\right) /$ $V_{T O T}$. This measure is sometimes denoted by IMA (index of motor abundance) (Serrien, Witterzeel, \& Baeyens, 2018; Yen \& Chang, 2009) or $\Delta V$ (J. Park, Singh, Zatsiorsky, \& Latash, 2012; Robert, Zatsiorsky, \& Latash, 2008), or confusingly by T (Verrel, 2010) or $\sigma$ (Togo, Kagawa, \& Uno, 2016). I suggest using the notation of $D V$ or $\Delta V$.

Since these indexes of synergy are not usually distributed normally, before applying statistical hypothesis tests, they should be transformed. Log-transformation is suggested for the ratio, $R_{t}=\log \left(V_{U C M} /\right.$ $V_{O R T}$ ) (Hsu et al., 2007) and modified Fisher's z-transformation for $D V$ as $D V_{z}=$ $\left[\log \left(\frac{\left|D V_{L}\right|+D V}{D V_{U}-D V}\right)-\log \frac{\left|D V_{L}\right|}{D V_{U}}\right] / 2 \quad$ (Solnik et al., 2013), where $D V_{L}$ and $D V_{U}$ are the lower and the upper bounds of $D V$, respectively; which are calculated as $D V_{L}=-n / d$ and $D V_{U}=n /(n-d)$.

In summary, to avoid conflicts of notations and to facilitate a literature survey, I suggest the use of symbols $R$ and $R_{t}$ for the ratio of variances and its log-transformation, respectively. If the difference between the good and the bad variability is to be normalized to the sum of the two variances, this could be denoted by RMV, while after normalizing to $V_{T O T}$, the index could be symbolized by $D V$ or $\Delta V$.

\section{References}

1. Black, D. P., Smith, B. A., Wu, J., \& Ulrich, B. D. (2007). Uncontrolled manifold analysis of segmental angle variability during walking: preadolescents with and without Down syndrome. Experimental Brain Research, 183(4), 511-521.

2. Gianikellis, K., Sánchez-Margallo, F. M., Skiadopoulos, A., Sánchez-Margallo, J. A., \& de Mendoza Aranda, J. H. (2015). Head stabilization during minimal invasive surgery tasks: An uncontrolled manifold analysis. Procedia Manufacturing, 3, 1434-1441.

3. Hsu, W.-L., Chou, L.-S., \& Woollacott, M. (2013). Age-related changes in joint coordination during balance recovery. $A G E$, 35(4), 1299-1309. doi:10.1007/s11357-0129422-x

4. Hsu, W.-L., Scholz, J. P., Schoner, G., Jeka, J. J., \& Kiemel, T. (2007). Control and estimation of posture during quiet stance depends on multijoint coordination. Journal of neurophysiology, 97(4), 3024-3035.

5. Papi, E., Rowe, P. J., \& Pomeroy, V. M. (2015). Analysis of gait within the uncontrolled manifold hypothesis: Stabilisation of the centre 
of mass during gait. Journal of Biomechanics, 48(2), 324-331. Retrieved from http://www.sciencedirect.com/science/article/p ii/S0021929014006125

6. Park, E., Reimann, H., \& Schöner, G. (2016). Coordination of muscle torques stabilizes upright standing posture: an UCM analysis. Experimental Brain Research, 234(6), 1757. doi:10.1007/s00221-016-4576-x

7. Park, E., Schöner, G., \& Scholz, J. P. (2012). Functional synergies underlying control of upright posture during changes in head orientation. PLoS ONE, 7(8), e41583. Retrieved from https://journals.plos.org/plosone/article?id=10. 1371/journal.pone.0041583

8. Park, J., Singh, T., Zatsiorsky, V. M., \& Latash, M. L. (2012). Optimality versus variability: effect of fatigue in multi-finger redundant tasks. Experimental Brain Research, 216(4), 591-607.

9. Robert, T., Zatsiorsky, V. M., \& Latash, M. L. (2008). Multi-muscle synergies in an unusual postural task: quick shear force production. Experimental Brain Research, 187(2), 237253.

10. Scholz, J. P., \& Schöner, G. (1999). The uncontrolled manifold concept: identifying control variables for a functional task. Experimental Brain Research, 126(3), 289306.

11. Serrien, B., Witterzeel, E., \& Baeyens, J.-P. (2018). The Uncontrolled Manifold Concept Reveals That the Structure of Postural Control in Recurve Archery Shooting Is Related to Accuracy. Journal of Functional Morphology and Kinesiology, 3(3), 48.

12. Solnik, S., Pazin, N., Coelho, C. J., Rosenbaum, D. A., Scholz, J. P., Zatsiorsky, V. M., \& Latash, M. L. (2013). End-state comfort and joint configuration variance during reaching. Experimental Brain Research, 225(3), 431-442.

13. Tawy, G. F., Rowe, P., \& Biant, L. (2018). Gait variability and motor control in patients with knee osteoarthritis as measured by the uncontrolled manifold technique. Gait \& Posture, 59, 272-277. doi:10.1016/j.gaitpost.2017.08.015

14. Togo, S., Kagawa, T., \& Uno, Y. (2016). Uncontrolled manifold reference feedback control of multi-joint robot arms. Frontiers in computational neuroscience, 10, 69.

15. Verrel, J. (2010). Distributional properties and variance-stabilizing transformations for measures of uncontrolled manifold effects. Journal of Neuroscience Methods, 191(2), 166170.

16. Yen, J. T., \& Chang, Y.-H. (2009). Ratedependent control strategies stabilize limb forces during human locomotion. Journal of The Royal Society Interface, 7(46), 801-810. 